\title{
Peptidselektive Isolierung unmanipulierter T-Zellen für die adoptive Immuntherapie
}

\section{Peptide-Specific Isolation of Unmanipulated T cells for Adoptive Immunotherapy}

Autoren

Institut

\section{B. Eiz-Vesper, R. Blasczyk}

Institut für Transfusionsmedizin, Medizinische Hochschule Hannover, Hannover

\section{Schlüsselwörter}

- adoptive T-Zelltherapie

- Stammzell- und Organtransplantation

- humanes Zytomegalievirus

- pMHC-Multimere

Key words

- adoptive T cell therapy

- stem cell and organ transplantation

- human cytomegalovirus

- pMHC multimers

\section{Bibliografie}

Dol http://dx.doi.org/ 10.1055/s-0032-1328112 Transfusionsmedizin 2013; 3: 16-22 @ Georg Thieme Verlag KG Stuttgart · New York . ISSN 2191-8805

\section{Korrespondenzadresse} Prof. Dr. Britta Eiz-Vesper Institut für Transfusionsmedizin Medizinische Hochschule Hannover

Carl-Neuberg-Straße 1

30625 Hannover

eiz-vesper.britta@

mh-hannover.de

\section{Zusammenfassung \\ $\nabla$}

Infektionen oder Reaktivierungen durch persistierende Viren, wie z. B. dem humanen Zytomegalievirus und dem Epstein-Barr-Virus, oder lytische Viren, wie z.B. dem Adenovirus, können sehr problematisch sein und durch teils schwere Verläufe zur Sterblichkeit nach Stammzell- und Organtransplantation beitragen. Es konnte gezeigt werden, dass der adoptive Transfer von antigenbzw. virusspezifischen T-Lymphozyten des seropositiven Spenders die spezifische Immunität im Patienten rekonstituiert und das Risiko einer Graft-versus-Host-Erkrankung minimal ist. Bereits eine geringe Zahl dieser antigenspezifischen T-Zellen führt zu klinischen Ansprechraten. Effektive Verfahren zur Aufreinigung dieser Zellen und deren klinische Effizienz wurden gezeigt.

\section{Allogene hämatopoetische Stammzelltransplantation \\ $\nabla$}

Die Transplantation von hämatopoetischen Stammzellen stellt eine potenziell kurative Therapieform für eine Reihe von hämatologischen und nicht hämatologischen Systemerkrankungen dar [1]. Das Prinzip der allogenen hämatopoetischen Stammzelltransplantation (hematopoietic stem cell transplantation, HSCT) ist es, das blutbildende System und das Immunsystem eines Patienten durch Stammzellen eines gesunden gewebeverträglichen Spenders vollständig zu ersetzen und durch das neue Immunsystem einen Graft-versus-Leukämie-(Graft-versus-Leukemia, GvL-)Effekt zu erreichen. Die hämatopoetischen Stammzellen werden aus Knochenmark, mobilisierten peripheren Blutzellen und aus Nabelvenenblut gewonnen. Nach Transplantation regeneriert sich ein neues Immunsystem aus den transplantierten Stammzellen des Spenders.

\section{Abstract \\ $\nabla$}

Infection with and reactivation of human cytomegalovirus, Epstein-Barr virus, and adenovirus are frequent and can lead to severe complications in immunocompromised recipients after hematopoietic stem cell transplantation or solid organ transplantation. These serious adverse events are associated with a significant morbidity and mortality. Adoptive immunotherapy with virus-specific cytotoxic effector $\mathrm{T}$ cells derived from seropositive donors can rapidly reconstitute antiviral immunity of the patient with no acute toxicity or increased risk of GvHD following transplantation. Only small numbers of antigen-specific $T$ cells are required to improve the transplantation outcome. Strategies to isolate the specific $\mathrm{T}$ cells are already established and the efficiency of adoptively transferred cells was shown.

\section{Bedeutung der T-Zellen in der allogenen HSCT \\ $\nabla$}

Spezifische T-Lymphozyten im allogenen Stammzelltransplantat sind entscheidend für das Transplantatüberleben und die Induktion des Therapie unterstützenden GvL-Effekts, der in erster Linie auf die Aktivierung von immunkompetenten Spender-T-Zellen durch verbliebene leukämische Blasten im Patienten zurückzuführen ist. Sind diese Zellen spezifisch gegen Pathogene, z. B. viraleErreger(Zytomegalievirus, HCMV; Epstein-BarrVirus, EBV; Adenovirus, ADV) und Pilze (Aspergillus) gerichtet, dann induzieren sie den Graft-versus-Infektion-(Graft-versus-Infection, GvI-)Effekt und ermöglichen so die Bekämpfung von Infektionen und Reaktivierungen durch diese opportunistischen Erreger.

Auf der anderen Seite jedoch können T-Zellen Ursache für die Graft-versus-Host-Erkrankung (Graft-versus-Host Disease, GvHD) sein. Unter 
GvHD versteht man die klinische Manifestation der immunologischen Auseinandersetzung der vom Spender stammenden immunkompetenten T-Zellen mit den Organen und Zellen des Empfängers. Besondere Risikofaktoren für die Entwicklung einer schweren akuten GvHD sind ein nicht verwandter Spender, HLA-Mismatch, weiblicher Spender bei männlichem Empfänger, hohes Lebensalter und vorangegangene Infektionen des Empfängers mit Herpesviren [2].

\section{Donor-Lymphozyten-Infusion und adoptive Immuntherapie zur Behandlung von Leukämien $\nabla$}

Bereits 1956 wurde erstmals von Barnes et al. die These veröffentlicht, dass eine Reaktion des Knochenmarks gegen die leukämischen Blasten zu deren Eliminierung führt [3]. Mathé et al. waren die ersten, die diesen GvL-Effekt für Transplantationserfolge im Menschen verantwortlich machten und die dafür den Begriff „adoptive Immuntherapie“ prägten [4]. Die adoptive Immuntherapie mit antigenspezifischen T-Zellen ist eine vielversprechende Therapieoption in der Behandlung von viralen (HCMV, EBV, ADV, HIV) und fungalen (Aspergillus) Infektionen ([5-19] ( $\triangle$ Abb. 1). Auch in der Therapie von soliden Tumoren und leukämischen Erkrankungen findet die Immuntherapie mit spezifischen T-Zellen Einsatzmöglichkeiten [20-26].

Die infundierten T-Zellen spielen eine wichtige Rolle bei der Wiederherstellung und Verbesserung der Immunfunktion nach aggressiven zytotoxischen Therapien ( $\bullet$ Abb. $\mathbf{1}$ a). Auch der rasche Wiederanstieg der Lymphozyten verbessert das Outcome der Patienten nach HSCT $[2,27]$.

Donor-Lymphozyten-Infusionen (DLI) bestehen aus nicht weiter präpariertem Vollblut oder aus durch Leukapherese gewonnenen mononukleären Zellen des Spenders ( $\boldsymbol{Q}$ Abb. $\mathbf{1} \mathbf{b}$ ). Als wirksamer Bestandteil werden in erster Linie die T-Zellen und die NK-Zellen angesehen. Die adoptive Immuntherapie mittels DLI wird erfolgreich eingesetzt zur Behandlung des Leukämie-Rezidivs bei CML, AML und multiplem Myelom nach allogener HSCT. Verantwortlich dafür ist der durch die übertragenen Spender-T-Zellen vermittelte GvL-Effekt. Besondere Bedeutung in der T-Zell-abhängigen Erkennung der leukämischen Zellen scheinen derzeit MinorHistokompatibilitätsantigene (z.B. HA-1, HA-2, HB-1 und UTY), sowie Leukämie-assoziierte Antigene (z.B. Proteinase-3, WT-1, h-TERT, hdm-2) zu haben $[20,23,28]$. Der kurative Effekt der DLI unter Verwendung von T-Zellen, die gegen GvL-assoziierte Minor-Histokompatibilitätsantigene gerichtet sind, konnte durch langandauernde komplette Remissionen nach DLI gezeigt werden [29-32].

\section{HCMV-Infektionen nach allogener hämatopoetischer Stammzelltransplantation \\ $\nabla$}

In den ersten 10-28 Tagen nach HSCT wird die Infektionsgefahr insbesondere durch eine ausgeprägte Neutropenie geprägt [33]. Diese begünstigt vor allem die Entstehung bakterieller Infekte. Auch in der späten Posttransplantationsphase (nach Tag 100 nach HSCT), werden bei Patienten mit chronischer GvHD hauptsächlich bakterielle Infekte beobachtet, die auf mangelhafte IgASekretionsleistung, Granulozytendefekte sowie quantitative wie auch qualitative B- und T-Zell-Defekte zurückzuführen sind. In der mittleren Posttransplantationsphase (von der hämatopoetischen Rekonstitution bis Tag 100 nach HSCT) ist die Infektion

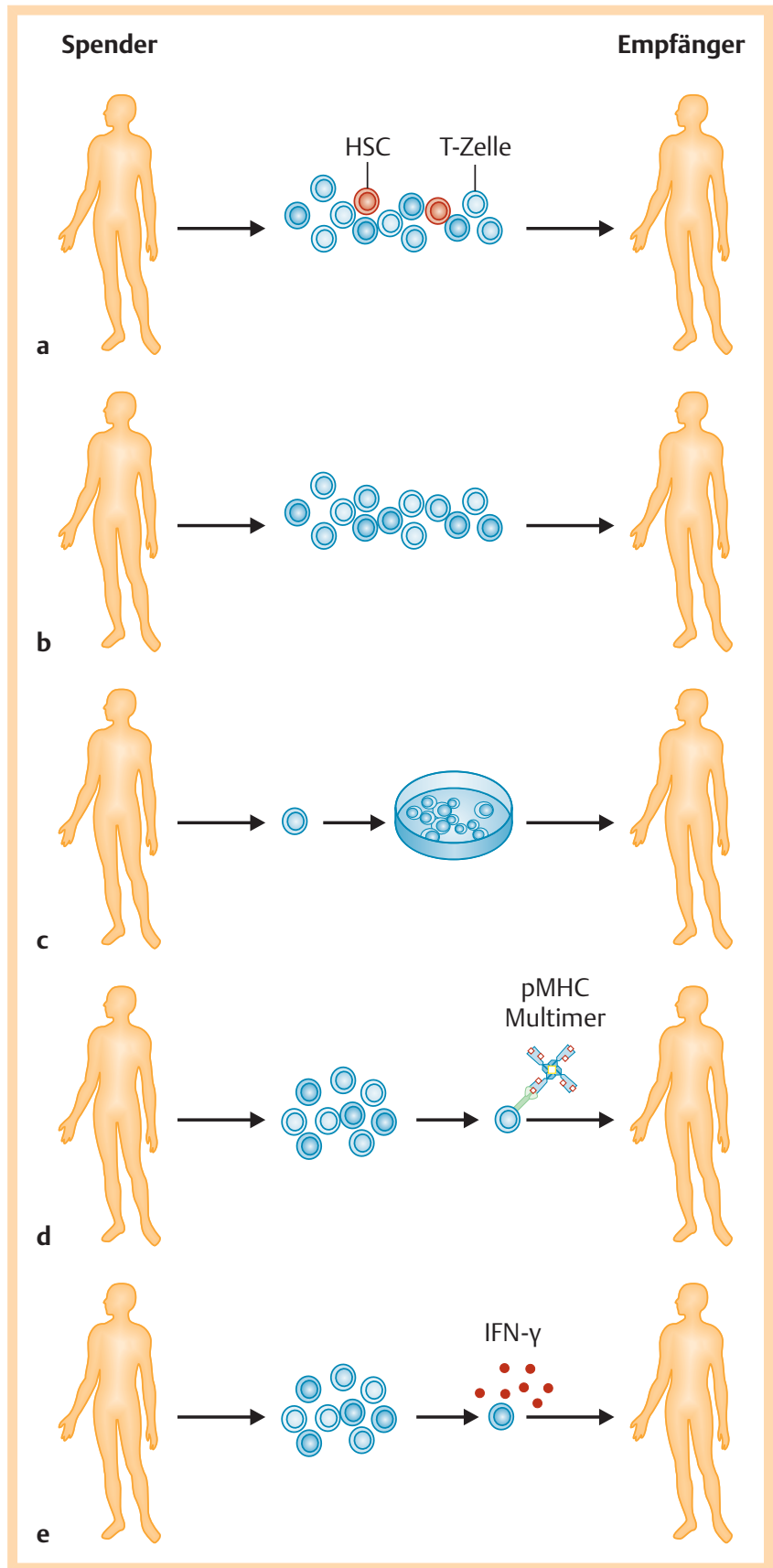

Abb. 1 Entwicklung der adoptiven T-Zell-Immuntherapie. a Mit der Übertragung von residualen T-Zellen im Transplantat wurde erstmals die immuntherapeutische Bedeutung der T-Zellen gezeigt. b Donor-Lymphozyten-Infusionen (DLI) bestehen aus unmanipulierten Spenderzellen. c Kultivierung und Expandierung spezifischer Zellen vor Transfusion. d Direkte Isolierung der antigenspezifischen Zellen mittels pMHC-Multimer-Technologie. e Isolierung antigenspezifischer IFN-Y sekretierender Zellen nach kurzer In-vitro-Stimulation. HSC = hämatopoetische Stamzelle (haematopoietic stem cell) (modifiziert nach [72]).

mit HCMV die bedrohlichste Infektion. Trotz neuer Diagnoseund Therapieverfahren stellt die HCMV-Reaktivierung bzw. -Neuinfektion bei Stammzell-Transplantierten immer noch ein großes Risiko dar. 40-70\% der HCMV-seropositiven Patienten erkranken nach einer HSCT an einer HCMV-Infektion [7,34-39]. Die HCMV-Infektion stellt mit die häufigste Todesursache bei Patienten nach allogener Stammzelltransplantation dar. 
Neben Infektionen des Gastrointestinaltrakts, der Leber und des hämatopoetischen Systems weist vor allem die interstitielle Pneumonie (IP) eine sehr hohe Letalität auf. Durch Verbesserungen im Rahmen der Infektionsprävention ist die Inzidenz der frühen HCMV-Erkrankung nach HSCT von 20-30\% auf 3-6\% gesunken. Die Mortalitätsrate ist aber trotz Behandlung mittels Ganciclovir und HCMV-Immunglobulin mit 30-50\% nach wie vor sehr hoch [7].

Die antivirale Theapie bei dokumentiertem HCMV-Nachweis bei Patienten nach allogener HSCT erfolgt routinemäßig mit den Virustatika Ganciclovir und Foscarnet. Ganciclovir ist ein HCMVbzw. Herpesvirus-spezifischer Guanosin-Antimetabolit, der durch die UL97-Kinase des HCMV phosphoryliert wird. Seine hohe Potenz, die Virusreplikation zu hemmen, beruht darauf, dass eine große Menge an aktiver, 3-fach phosphorylierter Wirkform in den HCMV-infizierten Zellen generiert wird. In dieser Form ist das Ganciclovir in der Lage, die virale DNA-Polymerase UL54 des HCMV zu hemmen. Ganciclovir hat erhebliche Nebenwirkungen, wovon an erster Stelle die Knochenmarktoxizität mit folgender Myelosuppression zu nennen ist. Die virustatische Wirkung von Foscarnet beruht auf einer direkten allosterischen Hemmung viraler Enzyme wie der DNA-Polymerase und der Reversen Transkriptase. Foscarnet hat ein anderes Nebenwirkungsspektrum als Ganciclovir, hier wird der Einsatz vor allem durch die Nephrotoxizität limitiert. Die antiviralen Therapeutika führen nicht immer zu einer vollständigen Unterdrückung des Virus, sodass zunehmend Resistenzen gegen diese Virustatika auftreten.

\section{Die Entwicklung der adoptiven Immuntherapie am Bespiel der Behandlung von HCMV-Infektionen nach allogener hämatopoetischer Stammzelltransplantation}

Da immer häufiger von Virustatika-resistenten HCMV-Isolaten nach HSCT berichtet wird und die Virustatikatherapie zudem mit erheblichen Nebenwirkungen verbunden ist, wird intensiv nach Alternativen zur Behandlung und Prävention der HCMV-Erkrankung gesucht. 1995 wurde erstmals von Walter et al. beschrieben, dass ein adoptiver Immuntransfer nach Transplantation mit HCMV-spezifischen zytotoxischen T-Lymphozyten (cytotoxic T cells, CTLs) die Inzidenz schwerer HCMV-Infektionen drastisch reduzierte [18]. Eine fehlende Rekonstitution der HCMV-spezifischen Immunantwort nach allogener HSCT ist entscheidend für die Entwicklung einer HCMV-Erkrankung [5, 7,9, $13,16]$.

Verschiedene Methoden zur Generierung HCMV-spezifischer CD8+ und CD4+ T-Zellen aus HCMV-seropositiven Spendern durch Stimulation der mononukleären Zellen des peripheren Blutes (peripheral blood mononuclear cells, PBMCs) mit Antigen präsentierenden Zellen (antigen presenting cells, APC) sind beschrieben ( $\bullet$ Abb. 1 c). Die Ex-vivo-Induktion HCMV-spezifischer CTLs mittels HCMV-infizierter autologer Fibroblasten als Stimulatorzellen eignet sich zwar prinzipiell zur Generierung virusspezifischer T-Zellen in vitro, weist aber auch einige Nachteile auf, da es sich bei Fibroblasten um keine professionellen APCs handelt [18]. Eine andere Methode verwendet EBV-transfizierte LCLs als Feeder-Zellen, in denen mittels retroviraler Vektoren das HCMVpp65-Protein zur Expression gebracht wird [40]. Für den klinischen Einsatz sind diese Methoden jedoch ungeeignet, da die Anwesenheit von HCMV- oder EBV-Viren ein nicht zu unterschätzendes Infektionsrisiko für die Patienten darstellt.
Eine alternative Methode setzt artifiziell Antigen präsentierende Zellen (aAPCs) ein, um antigenspezifische T-Zellen zu expandieren [41]. Als azelluläre aAPCs können magnetische Beads [42,43], artifizielle Liposomen [44] und Biomembranderivate [45-47] eingesetzt werden. Der Einsatz von aAPCs zeigt viele Vorteile. So können diese leicht mit dem zu untersuchenden HLA-PeptidKomplex beladen werden, und die Generierung von antigenspezifischen T-Zellen ist einfach reproduzierbar. Durch Kopplung an kostimulatorische Moleküle wie anti-CD28, CD80 und CD154 kann die T-Zell-Reaktivität verbessert werden. Ein weiterer Vorteil von aAPCs ist auch ihre Nutzung zur Induktion und Generierung von antigenspezifischen CD4+ T-Helfer-Zellen, wodurch ein gemeinsamer Transfer von CD4+ und CD8+ T-Zellen ermöglicht wird $[42,48]$.

Erfolgreich werden auch dendritische Zellen (dendritic cells, DCs) als professionell Antigen präsentierende Zellen oder nicht weiter aufgereinigte PBMCs, die entweder mit HCMV-Peptiden, oder Lysaten aus HCMV-infizierten Zellen oder mit HCMV-Antigen gepulst werden, zur Induktion der spezifischen T-Zellen eingesetzt [49-52] (ه Abb. 1 c). Ein Nachteil dieser Methode ist jedoch die arbeitsintensive und sehr zeitaufwendige Generierung der DCs und die Ex-vivo-Expansion der spezifischen CTLs über mehrere Wochen. Ein so hergestelltes Präparat würde als ATMP (Advanced Therapy Medicinal Products) klassifiziert werden und damit dem seit 2009 europaweit zentralisiertem Zulassungsverfahren durch die European Medicinal Agency (EMA) unterliegen, um die Sicherheit, Wirksamkeit und Qualität von ATMP-Produkten zu bewerten. Die Bewertung der Zulassungsunterlagen erfolgt durch das dafür gegründete Komitee für neuartige Therapien (Committee for Advanced Therapies, CAT).

\section{Anreicherung antigenspezifischer T-Zellen mittels Zytokin-Sekretions-Assay \\ $\nabla$}

Daher wurde intensiv an Methoden geforscht, die es ermöglichen, unter Verwendung nicht infektiöser Materialien und unfraktionierter PBMCs innerhalb relativ kurzer Zeit eine für den adoptiven Transfer ausreichende Menge antiviraler T-Zellen zu isolieren. Derzeit werden hier im Wesentlichen 2 Strategien zur direkten Aufreinigung verfolgt: (1) Anreicherung antigenspezifischer T-Zellen aufgrund der Sekretion von Effektormolekülen (z.B. Interferon- $\gamma$, IFN- $\gamma$, cytokine secretion assay) ( $\bullet$ Abb. 1 c) oder der Expression von Zelloberflächenmarkern (z.B. CD154) nach kurzer In-vitro-Antigenstimulation [9,13,14,16,53-55] und (2) Anreicherung spezifischer T-Zellen über den T-Zell-Rezeptor (TZR) unter Verwendung Peptid-MHC (pMHC) multimerer Moleküle ( Abb. 1 d, ๑ Abb. 2) [56-59].

Die Isolierung antigenspezifischer T-Zellen mittels Zytokin-Sekretions-Assay ermöglicht, je nach Verwendung des entsprechenden Stimulans (rekombinantes Protein, überlappende Peptidpools), die Isolierung CD4+ und/oder CD8+ antiviraler T-Zellen. Diese Methode berücksichtigt die Tatsache, dass für eine langandauernde Persistenz transferierter CD8+ T-Zellen die zusätzliche Anwesenheit von CD4+ T-Helferzellen erforderlich zu sein scheint. CD4+ T-Helferzellen sezernieren Wachstumsfaktoren, wie z.B. Interleukin-2, oder vermitteln kostimulierende Signale, z. B. über CD40/CD154- oder CD80/CD28-Interaktionen, die eine Aufrechterhaltung der zytotoxischen T-Zell-Antwort unterstützen $[60,61]$. So konnte gezeigt werden, dass eine Abnahme der Immunantwort gegen HCMV durch die infundierten zytotoxischen T-Zellen gerade bei den Patienten auftrat, die keine 

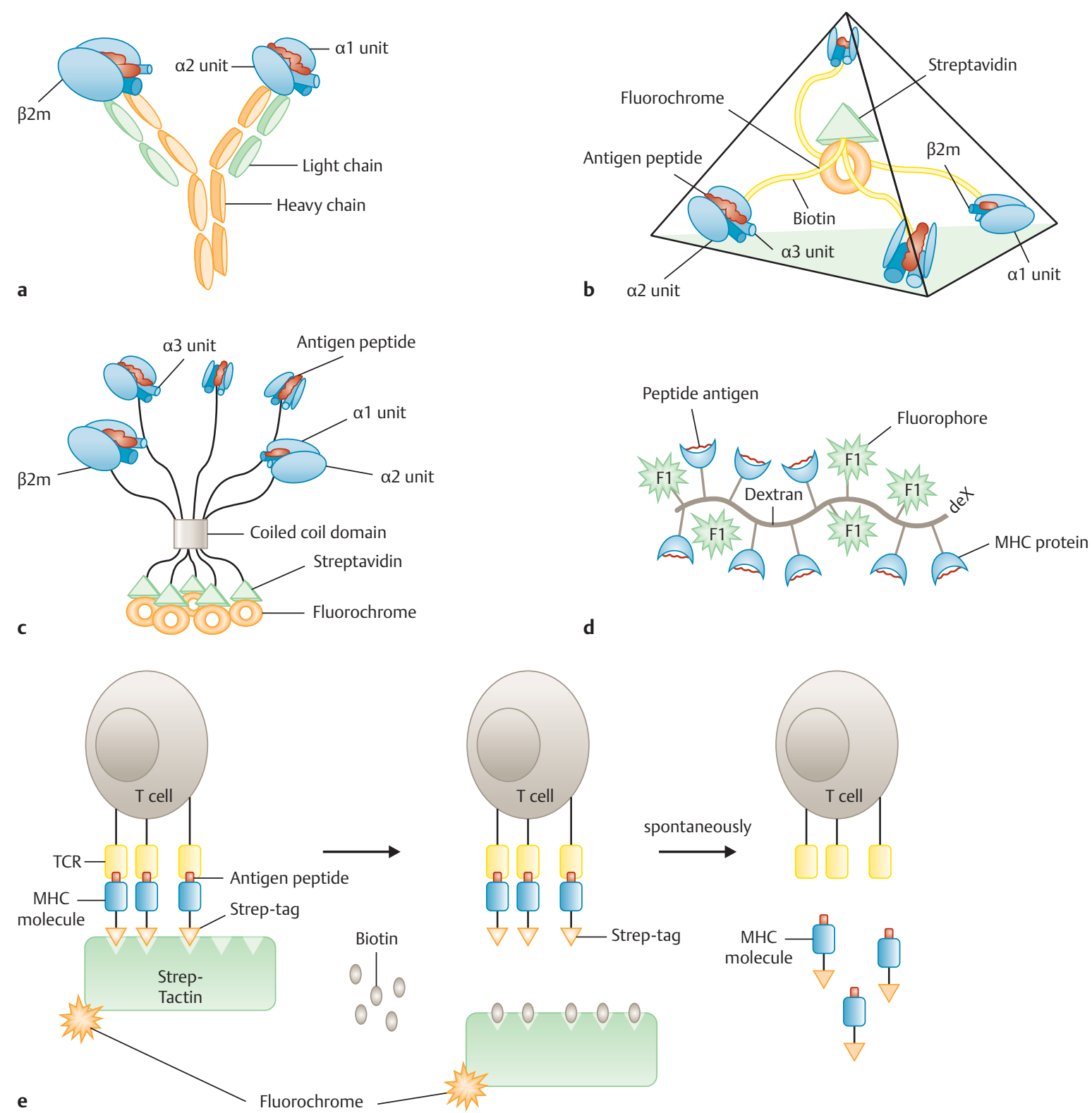

e
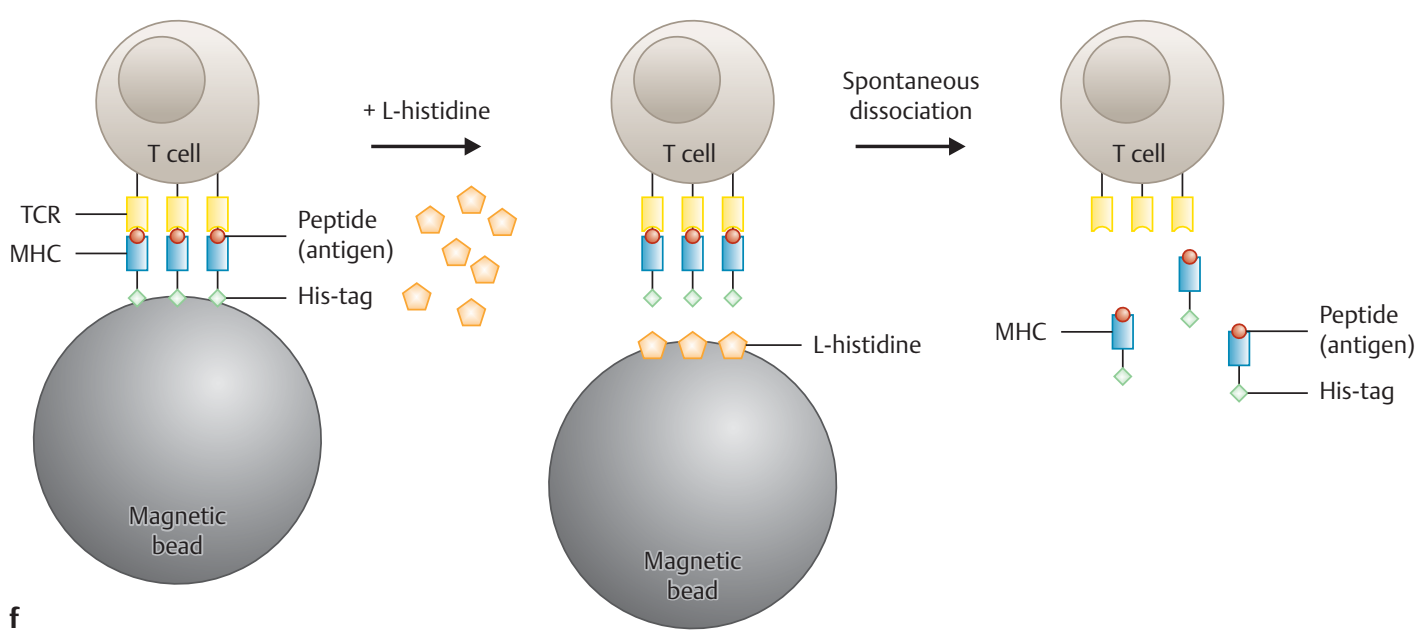

Abb. 2 pMHC-Multimere. a Dimere bestehen aus 2 pMHC-Molekülen, die über die VH Regionen von murinen IgG1 fusioniert sind. b Vier pMHC-Moled Dextran bildet das Rückgrat der Dextramere. e Streptamere und f Histamere bieten den Vorteil einer reversiblen Zellmarkierung und ermöglich damit küle sind über ein zentrales Streptavidinmolekül verbunden und bilden einen die Anreicherung unmanipulierter T-Lymphozyten (aus [20, 59, 64, 67]). tetrameren Komplex. c Pentamere bestehen aus 5 pMHC-Molekülen. 
HCMV-spezifische CD4+ T-Helfer-Antwort zeigten [18]. Im Gegenteil, das Auftreten einer T-Helfer-Antwort nach Infusion ging einher mit einer anhaltenden oder zunehmenden HCMV-Antwort der zytotoxischen T-Zellen. Auf der anderen Seite jedoch, sind die Reinheiten der isolierten Zellpopulationen nach Stimulation mit überlappenden Peptidpools mit ca. 50\% IFN- $\gamma$-sezernierenden CD3+ T-Lymphozyten [16] deutlich geringer im Vergleich zu pMHC-Multimer-aufgereinigten Präparaten [58] und bergen damit auch ein vermeintlich größeres Potenzial der Übertragung von alloreaktiven T-Zellen, die dann wiederum zur Induktion oder Verstärkung einer bereits bestehenden GvHD führen könnten. Peggs und Kollegen konnten zeigen, dass der Transfer von $1 \times 10^{4}$ CD3+ T-Zellen/kg (durchschnittlich 2840 CD4+ und 630 CD8+ CMV-spezifische T-Zellen/kg, 43,9\% IFN- $\gamma$-positiv) zu effektiven Ansprechraten und keinem signifikanten Anstieg von GvHD in den Patienten führte [16]. Aufgrund der - wenn auch kurzen In-vitro-Stimulationszeit werden diese Präparate derzeit als ATMP klassifiziert.

\section{Anreicherung unmanipulierter antigenspezifischer T-Zellen mittels pMHC-Multimeren}

Virusspezifische und die Mehrzahl alloreaktiver T-Zellen erkennen MHC-Moleküle in peptidabhängiger Weise. Die Identifizierung Virus- und Allopeptid-restringierter T-Lymphozyten erfolgt traditionell unter Verwendung funktioneller Asssays über die Bestimmung der zytotoxischen/zytolytischen Aktivität der induzierten T-Zelle. Ergebnisse zeigten jedoch, dass diese proliferationsabhängigen Versuche technisch sehr schwierig und mit einem hohen Anteil unspezifischer Ergebnisse belastet sind. Zum anderen ist nur die Detektion einer kleinen Population antigenspezifischer Zellen möglich.

Antigene Epitope, die durch MHC-Moleküle präsentiert werden, werden mit hoher Spezifität durch T-Zell-Rezeptoren gebunden. Die Bindung monomerer pMHC-Moleküle an die TZRs ist jedoch kurzlebig und zeigt geringe Bindungsaffinitäten mit einer verzögerten Assoziation und raschen Dissoziation [62]. Mit der Beschreibung von multimeren pMHC-Molekülen gelang es, eine dauerhafte Markierung der T-Zellen durch eine stabile pMHC-TZR-Bindung zu ermöglichen. Seit der Tetramerbeschreibung von John Altman [63] können antigenspezifische T-Zellen direkt mittels Durchflusszytometrie identifiziert, visualisiert, analysiert und quantifiziert werden. So konnten peptidselektive CD8+ T-Zellen nach viralen Infektionen sowie bei Autoimmunerkrankungen und Tumorpatienten nachgewiesen werden. Inzwischen wurden zahlreiche Technologien und Verfahren zur Herstellung epitopbindender multimerer pMHC Moleküle, wie z.B. Dimere, Tetramere, Pentamer, Dextramere, Streptamere, und Histamere etabliert ( Abb. 2) [63-68]. Zur Generierung multimerer pMHC-Moleküle werden rekombinante MHC-Klasse-Ibzw. -II-Moleküle mit spezifischen Tags (z.B. Strep-Tag, His-Tag) oder Enzym-Erkennungssequenzen (z.B. für die Biotinylierung) exprimiert, durch Zugabe von rekombinantem $\beta 2$-Mikroglobulin (für HLA Klasse I) und der entsprechenden Peptidantigene ( 8 bis 10 Aminosäuren für MHC Klasse I, 9-12 Aminosäuren für MHC Klasse II) unter Redox-Bedingungen gefaltet und über deren Tags multimerisiert. Die Expression der Moleküle erfolgt überwiegend im prokaryonten System mit anschließender Proteinfaltung. Der Komplex aus MHC-Molekül und gebundenem Peptid wird von einer T-Zelle mit dem passenden TZR erkannt und gebunden. pMHC-Multimere werden mit Fluoreszenzfarbstoffen konjugiert, um die T-Zellen durchflusszytometrisch sichtbar zu machen $[63,66,67]$.

Im Falle der erstbeschriebenen Tetramere wurden 4 rekombinante pMHC-Moleküle (tetra, gr.; vier) über die Kopplung des Biotinrestes an Avidin/Streptavidin multimerisiert [63]. Pentamere bestehen aus 5 pMHC-Molekülen (penta, gr.; fünf), die über ein Trägermolekül (coiled-coil domain) verbunden sind [68]. Zur Generierung von Dextrameren werden pMHC-Moleküle an eine Polymerkette (Dextran) gebunden [64]. Untersuchungen zur Spezifität und Sensitivität in der Verwendung unterschiedlicher Multimere ergaben vergleichbare antigenspezifische CD8+ TZell-Frequenzen [59].

Multimere pMHC-Moleküle werden bereits seit Längerem zur Detektion und Isolierung antigenspezifischer T-Zellen eingesetzt. Mit der Entwicklung reversibler pMHC-Multimere (Streptamere, Histamere) [66,67], die die komplette Dissoziation der Reagenzien, die zur Markierung oder Isolierung von T-Zellen nötig sind, ermöglichen, finden diese nun auch Einsatz in der Aufreinigung spezifischer Zellen für den adoptiven Transfer [58].

Streptamere sind Multimere, die aus 4 pMHC-Komplexen bestehen, die über den Strep-tagIII an Strep-Tactin gebunden sind. Strep-Tactin, eine modifizierte Form des Streptavidins, stellt somit das Rückgrat des Streptamers dar ( Abb. 2e; [66]). Da d-Biotin eine höhere Bindungsaffinität zu Strep-Tactin besitzt als Strep-tagIII, kann durch Zugabe von Biotin das Rückgrat abgelöst werden. Die resultierende monovalente pMHC-TZR-Interaktion ist schwach, und die pMHC-Monomere dissoziieren spontan von den TZR (reversible Färbung). Die Geschwindigkeit der Dissoziation der pMHC-Moleküle von der T-Zelle hängt von der Bindungsaffinität des pMHC-TZR-Komplexes ab. Die Multimerisierung von Histameren erfolgt durch die Bindung des 6×His Tag am pMHC-Molekül an Cobalt-beschichtete magnetische Beads ( Abb. 2f; [67]). Durch Zugabe des natürlichen Kompetitors LHistidin kommt es zur Dissoziation der pMHC-Moleküle von den magnetischen Beads, auf welche die Dissoziation der pMHC-Moleküle von den TZRs folgt. Durch die Reversibilisierung der Bindung können mögliche klinische Nebenwirkungen des verwendeten Selektionsmarkers (Toxizität, Immunogenität) ausgeschlossen werden, und die aufgereinigten T-Zellen unterscheiden sich phänotypisch und funktionell nicht von den in vivo vorkommenden T-Zellen.

\section{Klinische Erfahrungen der peptidselektiven Anreicherung unmanipulierter T-Zellen für die adoptive Immuntherapie}

Die Streptamer-Technologie bietet die Möglichkeit, mit klinisch zugelassenen Streptameren eine Selektion von antigenspezifischen T-Zellen unter Good Manufacturing Practice (GMP)-Bedingungen für einen adoptiven T-Zelltransfer durchzuführen $[52,58,66,69]$. Im Rahmen einer multizentrischen klinischen Phase-I-Prüfstudie werden derzeit Patienten mit mangelnder Immunrekonstitution und rezidivierender HCMV-Reaktivierung mit Streptamer-aufgereinigten CD8+ T-Lymphozyten behandelt. Als Spender der HCMVpp65-spezifischen CD8+ T-Lymphozyten fungieren hier die HCMV-seropositiven gesunden Stammzellspender.

Erste Ergebnisse zur klinischen Anwendung mittels StreptamerTechnologie aufgereinigter HCMV-spezifischer CD8+ T-Zellen wurden im vergangenen Jahr von der Gruppe um Anita Schmitt publiziert [58]. Es wurden 2 Patienten mit AML (akute myeloide 
Leukämie) und ALL (akute lymphatische Leukämie), die nach Transplantation von G-CSF-mobilisierten Stammzellen eine therapieresistente hochgradige CMV-Antigenämie zeigten, mit HCMVpp65/HLA-B7- bzw. HCMVpp65/HLA-A24-spezifischen T-Zellen behandelt. Die mittels Streptamer-Technologie aufgereinigten T-Zellen zeigten eine besonders hohe Reinheit (>95\%). Durch den spezifischen adoptiven T-Zell-Transfer von $2,2 \times 10^{5}$ HCMVpp65/HLA-B7-spezifischen bzw. $37 \times 10^{5}$ HCMVpp65/ HLA-A24-spezifischen CD8+ T-Zellen/kgKG gelang es, die Patienten auch langfristig und nachhaltig vor HCMV-Reaktivierungen zu bewahren [58].

Wichtigste Voraussetzung für den effektiven Einsatz von pMHCMultimer-aufgereinigten T-Lymphozyten im Rahmen der Immuntherapie ist die Kenntnis immundominanter T-Zell-Epitope für verschiedene HLA-Allele und Erreger. Nicht immer ist die Seropositivität eines potenziellen T-Zell-Spenders auch ein Hinweis für das Vorhandensein der entsprechenden peptidspezifischen Gedächnis-T-Zellpopulation (memory T cells). Umfangreiche Studien zeigen, dass selbst für das immundominante HLA-A*02:01-restringierte HCMVpp65 (495-503)-Epitop nur in 48-71\% HLA-A*02:01-, HCMV-seropositiver gesunder Spender T-Zellfrequenzen gegen dieses Antigen detektierbar sind und der prozentuale Anteil stark variiert (0,15-13,55\%) [58,59,70] (Sukdolak et al., submitted). Diese Ergebnisse zeigen, wie wichtig ein gewissenhaftes T-Zell-Spender-Screening und die Multimeranalyse im Zusammenhang mit der serologischen Testung zur Spenderauswahl ist (Dieks et al., submitted). Die Bestimmung der Frequenz von antigenspezifischen CD8+ T-Zellen potenzieller HCMV-seropositiver Stammzellspender ist entscheidend für die erfolgreiche Aufreinigung der spezifischen Zellen und die Applikation dieser bei Patienten mit einer therapieresistenten hochgradigen HCMV-Reaktivierung nach allogener HSCT ohne messbare HCMVpp65-spezifische T-Zellen [71].

Nach den ersten erfolgversprechenden Ergebnissen des klinischen Einsatzes von Streptamer-isolierten T-Zellen in der Behandlung von HCMV-Infektionen wird derzeit der klinische Einsatz von Streptamer-aufgereinigten Lymphozyten auch für weitere virale Epitope (z.B. EBV und ADV) und Leukämie-assoziierte Antigene (LAAs) geprüft. Im letzteren Ansatz ist das Wilms-Tumor-Gen 1 (WT1), welches differenziell auf leukämischen Blasten überexprimiert wird, das entsprechende Target-Epitop [20].

\section{Interessenkonflikt}

$\nabla$

Es bestehen keine finanziellen Interessenkonflikte in Bezug auf dieses Manuskript.

\section{Literatur}

1 Ljungman $P$ et al. Allogeneic and autologous transplantation for haematological diseases, solid tumours and immune disorders: current practice in Europe 2009. Bone Marrow Transplant 2010; 45: 219-234

2 Gooley TA et al. Reduced mortality after allogeneic hematopoietic-cell transplantation. N Engl J Med 2010; 363: 2091-2101

3 Barnes DW et al. Treatment of murine leukaemia with $\mathrm{X}$ rays and homologous bone marrow; preliminary communication. Br Med J 1956; 2: 626-627

4 Mathe $G$ et al. Adoptive immunotherapy of acute leukemia: experimental and clinical results. Cancer Res 1965; 25: 1525-1531

5 Brestrich $\mathrm{G}$ et al. Adoptive T-cell therapy of a lung transplanted patient with severe CMV disease and resistance to antiviral therapy. Am J Transplant 2009; 9: 1679-1684

6 Doubrovina E et al. Adoptive immunotherapy with unselected or EBVspecific T cells for biopsy-proven EBV+ lymphomas after allogeneic hematopoietic cell transplantation. Blood 2012; 119: 2644-2656
7 Einsele H, Kapp M, Grigoleit GU CMV-specific T cell therapy. Blood Cells Mol Dis 2008; 40: 71-75

8 Feuchtinger T et al. Safe adoptive transfer of virus-specific T-cell immunity for the treatment of systemic adenovirus infection after allogeneic stem cell transplantation. Br J Haematol 2006; 134: 64-76

9 Feuchtinger $T$ et al. Adoptive transfer of pp65-specific $T$ cells for the treatment of chemorefractory cytomegalovirus disease or reactivation after haploidentical and matched unrelated stem cell transplantation. Blood 2010; 116: 4360-4367

10 Haque $T$ et al. Allogeneic T-cell therapy for Epstein-Barr virus-positive posttransplant lymphoproliferative disease: long-term follow-up. Transplantation 2010; 90: 93-94

11 Heslop HE et al. Long-term outcome of EBV-specific T-cell infusions to prevent or treat EBV-related lymphoproliferative disease in transplant recipients. Blood 2010; 115: 925-935

12 Hoffman JA. Adenovirus infections in solid organ transplant recipients. Curr Opin Organ Transplant 2009; 14: 625-633

13 Mackinnon S et al. Adoptive cellular therapy for cytomegalovirus infection following allogeneic stem cell transplantation using virus-specific T cells. Blood Cells Mol Dis 2008; 40: 63-67

14 Moosmann A et al. Effective and long-term control of EBV PTLD after transfer of peptide-selected T cells. Blood 2010; 115: 2960-2970

15 Pagliara D, Savoldo B. Cytotoxic T lymphocytes for the treatment of viral infections and posttransplant lymphoproliferative disorders in transplant recipients. Curr Opin Infect Dis 2012; 25: 431-437

16 Peggs KS et al. Directly selected cytomegalovirus-reactive donor T cells confer rapid and safe systemic reconstitution of virus-specific immunity following stem cell transplantation. Clin Infect Dis 2011; 52: 49-57

17 Qasim W et al. Third-party virus-specific T cells eradicate adenoviraemia but trigger bystander graft-versus-host disease. Br J Haematol 2011; 154: 150-153

18 Walter EA et al. Reconstitution of cellular immunity against cytomegalovirus in recipients of allogeneic bone marrow by transfer of T-cell clones from the donor. N Engl J Med 1995; 333: 1038-1044

19 Zandvliet ML et al. Combined CD8+ and CD4+ adenovirus hexon-specific T cells associated with viral clearance after stem cell transplantation as treatment for adenovirus infection. Haematologica 2010; 95: $1943-$ 1951

20 Casalegno-Garduno $R$ et al. Wilms' tumor 1 as a novel target for immunotherapy of leukemia. Transplant Proc 2010; 42: 3309-3311

21 Hofmann S, Greiner J. Adoptive Immunotherapy after Allogeneic Hematopoietic Progenitor Cell Transplantation: New Perspectives for Transfusion Medicine. Transfus Med Hemother 2011; 38: 173-182

22 June $\mathrm{CH}$. Adoptive $\mathrm{T}$ cell therapy for cancer in the clinic. J Clin Invest 2007; 117: 1466-1476

23 Marijt WA et al. Hematopoiesis-restricted minor histocompatibility antigens HA-1- or HA-2-specific T cells can induce complete remissions of relapsed leukemia. Proc Natl Acad Sci U S A 2003; 100: 27422747

24 Rapoport AP et al. Combination immunotherapy using adoptive T-cell transfer and tumor antigen vaccination on the basis of hTERT and survivin after ASCT for myeloma. Blood 2011; 117: 788-797

25 Rosenberg SA, Dudley ME. Adoptive cell therapy for the treatment of patients with metastatic melanoma. Curr Opin Immunol 2009; 21: 233 240

26 Rosenberg SA et al. Adoptive cell transfer: a clinical path to effective cancer immunotherapy. Nat Rev Cancer 2008; 8: 299-308

27 Porter DL, June CH. T-cell reconstitution and expansion after hematopoietic stem cell transplantation: ' $T$ ' it up! Bone Marrow Transplant 2005; 35: 935-942

28 Doubrovina E et al. Mapping of novel peptides of WT-1 and presenting HLA alleles that induce epitope-specific HLA-restricted T cells with cytotoxic activity against WT-1(+) leukemias. Blood 2012; 120: 16331646

29 Hobo Wet al. Association of Disparities in Known Minor Histocompatibility Antigens with Relapse-Free Survival and Graft-versus-Host-Disease after Allogeneic Stem Cell Transplantation. Biol Blood Marrow Transplant 2012; DOI: 10.1016/j.bbmt.2012.09.008

30 Katagiri $T$ et al. Mismatch of minor histocompatibility antigen contributes to a graft-versus-leukemia effect rather than to acute GVHD, resulting in long-term survival after HLA-identical stem cell transplantation in Japan. Bone Marrow Transplant 2006; 38: 681-686

$31 \mathrm{Kolb} \mathrm{HJ} \mathrm{et} \mathrm{al.} \mathrm{Donor} \mathrm{leukocyte} \mathrm{transfusions} \mathrm{for} \mathrm{treatment} \mathrm{of} \mathrm{recurrent}$ chronic myelogenous leukemia in marrow transplant patients. Blood 1990; 76: 2462-2465 
32 Porter DL et al. Treatment of relapsed leukemia after unrelated donor marrow transplantation with unrelated donor leukocyte infusions. Blood 2000; 95: 1214-1221

33 Einsele $\mathrm{H}$ et al. Risk factors for treatment failures in patients receiving PCR-based preemptive therapy for CMV infection. Bone Marrow Transplant 2000; 25: 757-763

34 Fujita Y, Rooney CM, Heslop HE. Adoptive cellular immunotherapy for viral diseases. Bone Marrow Transplant 2008; 41: 193-198

35 Lilleri $D$ et al. Human cytomegalovirus-specific CD4+ and CD8+ T-cell reconstitution in adult allogeneic hematopoietic stem cell transplant recipients and immune control of viral infection. Haematologica 2008; 93: 248-256

36 Lilleri $D$ et al. Monitoring of human cytomegalovirus and virus-specific T-cell response in young patients receiving allogeneic hematopoietic stem cell transplantation. PLoS One 2012; 7: e41648

37 Ugarte-Torres A et al. Donor serostatus has an impact on cytomegalovirus-specific immunity, cytomegaloviral disease incidence, and survival in seropositive hematopoietic cell transplant recipients. Biol Blood Marrow Transplant 2011; 17: 574-585

38 Zhou W et al. Impact of donor CMV status on viral infection and reconstitution of multifunction CMV-specific T cells in CMV-positive transplant recipients. Blood 2009; 113: 6465-6476

39 Borchers $S$ et al. Tetramer monitoring to assess risk factors for recurrent cytomegalovirus reactivation and reconstitution of antiviral immunity post allogeneic hematopoietic stem cell transplantation. Transpl Infect Dis 2011; 13: 222-236

40 Sun $Q$ et al. Simultaneous ex vivo expansion of cytomegalovirus and Epstein-Barr virus-specific cytotoxic T lymphocytes using B-lymphoblastoid cell lines expressing cytomegalovirus pp 65. Blood 1999; 94: 3242-3250

41 Maus MV et al. HLA tetramer-based artificial antigen-presenting cells for stimulation of CD4+ T cells. Clin Immunol 2003; 106: 16-22

42 Oelke $M$ et al. Ex vivo induction and expansion of antigen-specific cytotoxic T cells by HLA-Ig-coated artificial antigen-presenting cells. Nat Med 2003; 9: 619-624

43 Paine A et al. Expansion of human cytomegalovirus-specific T lymphocytes from unfractionated peripheral blood mononuclear cells with artificial antigen-presenting cells. Transfusion 2007; 47: 2143-2152

44 Prakken $B$ et al. Artificial antigen-presenting cells as a tool to exploit the immune 'synapse'. Nat Med 2000; 6: 1406-1410

45 Amidi $M$ et al. Induction of humoral and cellular immune responses by antigen-expressing immunostimulatory liposomes. J Control Release 2012; 164: 323-330

46 Chaput $N$ et al. Exosomes for immunotherapy of cancer. Adv Exp Med Biol 2003; 532: 215-221

$47 \mathrm{Hsu} \mathrm{DH}$ et al. Exosomes as a tumor vaccine: enhancing potency through direct loading of antigenic peptides. J Immunother 2003; 26: 440-450

48 Levine BL et al. Large-scale production of CD4+ T cells from HIV-1-infected donors after CD3/CD28 costimulation. J Hematother 1998; 7: 437-448

49 Carlsson B et al. Ex vivo stimulation of cytomegalovirus (CMV)-specific $\mathrm{T}$ cells using CMV pp 65-modified dendritic cells as stimulators. $\mathrm{Br}$ J Haematol 2003; 121: 428-438

50 Lozza L et al. Simultaneous quantification of human cytomegalovirus (HCMV)-specific CD4+ and CD8+ T cells by a novel method using monocyte-derived HCMV-infected immature dendritic cells. Eur J Immunol 2005; 35: 1795-1804

51 Peggs K, Verfuerth S, Mackinnon S. Induction of cytomegalovirus (CMV)-specific T-cell responses using dendritic cells pulsed with CMV antigen: a novel culture system free of live CMV virions. Blood 2001; 97: 994-1000

52 Tischer $S$ et al. Heat shock protein 70/peptide complexes: potent mediators for the generation of antiviral T cells particularly with regard to low precursor frequencies. J Transl Med 2011; 9: 175
53 Feuchtinger T et al. Clinical grade generation of hexon-specific T cells for adoptive T-cell transfer as a treatment of adenovirus infection after allogeneic stem cell transplantation. J Immunother 2008; 31: 199-206

54 Peggs KS et al. Cytomegalovirus-specific T cell immunotherapy promotes restoration of durable functional antiviral immunity following allogeneic stem cell transplantation. Clin Infect Dis 2009; 49: 18511860

55 Rauser $G$ et al. Rapid generation of combined CMV-specific CD4+ and CD8+ T-cell lines for adoptive transfer into recipients of allogeneic stem cell transplants. Blood 2004; 103: 3565-3572

56 Casalegno-Garduno $R$ et al. Multimer technologies for detection and adoptive transfer of antigen-specific T cells. Cancer Immunol Immunother 2010; 59: 195-202

57 Cobbold $M$ et al. Adoptive transfer of cytomegalovirus-specific CTL to stem cell transplant patients after selection by HLA-peptide tetramers. J Exp Med 2005; 202: 379-386

58 Schmitt A et al. Adoptive transfer and selective reconstitution of streptamer-selected cytomegalovirus-specific CD8+ T cells leads to virus clearance in patients after allogeneic peripheral blood stem cell transplantation. Transfusion 2011; 51: 591-599

59 Yao J et al. Multimer staining of cytomegalovirus phosphoprotein 65specific $T$ cells for diagnosis and therapeutic purposes: a comparative study. Clin Infect Dis 2008; 46: e96-e105

60 Sarawar SR et al. Stimulation via CD40 can substitute for CD4 T cell function in preventing reactivation of a latent herpesvirus. Proc Natl Acad Sci U S A 2001; 98: 6325-6329

61 Schoenberger SP et al. T-cell help for cytotoxic T lymphocytes is mediated by CD40-CD40L interactions. Nature 1998; 393: 480-483

62 Matsui K et al. Kinetics of T-cell receptor binding to peptide/I-Ek complexes: correlation of the dissociation rate with T-cell responsiveness. Proc Natl Acad Sci U S A 1994; 91: 12862-12866

63 Altman JD et al. Phenotypic analysis of antigen-specific T lymphocytes. Science 1996; 274: 94-96

64 Batard P et al. Dextramers: new generation of fluorescent MHC class I/ peptide multimers for visualization of antigen-specific CD8+ T cells. J Immunol Methods 2006; 310: 136-148

65 Dal Porto J et al. A soluble divalent class I major histocompatibility complex molecule inhibits alloreactive T cells at nanomolar concentrations. Proc Natl Acad Sci U S A 1993; 90: 6671-6675

$66 \mathrm{Knabel} M$ et al. Reversible MHC multimer staining for functional isolation of T-cell populations and effective adoptive transfer. Nat Med 2002; 8: 631-637

67 Tischer $S$ et al. Establishment of the reversible peptide-major histocompatibility complex (pMHC) class I Histamer technology: tool for visualization and selection of functionally active antigen-specific CD8+ T lymphocytes. Int Immunol 2012; 24: 561-572

68 Duplan $V$ et al. Tracking antigen-specific CD8+ T cells in the rat using MHC class I multimers. J Immunol Methods 2007; 320: 30-39

69 Neudorfer J et al. Reversible HLA multimers (Streptamers) for the isolation of human cytotoxic T lymphocytes functionally active against tumor- and virus-derived antigens. J Immunol Methods 2007; 320: 119131

70 Paine A et al. Soluble recombinant CMVpp65 spanning multiple HLA alleles for reconstitution of antiviral CD4+ and CD8+ T-cell responses after allogeneic stem cell transplantation. J Immunother 2010; 33: 60-72

71 Egli A, Humar A, Kumar D. State-of-the-Art Monitoring of Cytomegalovirus-Specific Cell-Mediated Immunity After Organ Transplant: A Primer for the Clinician. Clin Infect Dis 2012; 55: 1678-1689

72 Moss P, Rickinson A. Cellular immunotherapy for viral infection after HSC transplantation. Nat Rev Immunol 2005; 5: 9-20 